\title{
SISTEM PENDUKUNG KEPUTUSAN PENILAIAN KINERJA PEGAWAI PELAYANAN ADMINISTRASI TERPADU KECAMATAN (PATEN) DI KECAMATAN PUCUK MENGGUNAKAN METODE AHP BERBASIS WEB
}

\author{
Ubaidilla Maghfur $^{1}$, M. Hasan Wahyudi ${ }^{2}$, Munif ${ }^{2}$ \\ ${ }^{1)}$ Mahasiswa Program Studi Teknik Informatika, Fakultas Teknik, Universitas Islam Lamongan \\ ${ }^{2)}$ Dosen Program Studi Teknik Informatika, Fakultas Teknik, Universitas Islam Lamongan \\ E-mail:ubedsaja@gmail.com ${ }^{1}$,hasanwahyudi@unisla.ac.id ${ }^{2}$,munif@unisla.ac.id ${ }^{3}$
}

\begin{abstract}
Decision Support System is Information management aids system that deals with the calculation and assessment of employees in sub-district service, many ways to assess employee performance but this system that I created, as in advance company this system is often in use. In this research using AHP method. Making this performance appraisal decision support system using a web system. The system was created can provide an appraisal to assess the work of employees in PATENT.
\end{abstract}

Keyword : Decision Support Systems, AHP, Web

\section{PENDAHULUAN}

Kualitas sumber daya manusia merupakan salah satu faktor yang diperlukan untuk meningkatkan produktivitas kinerja suatu instansi. Oleh karena itu diperlukan sumber daya manusia (SDM) yang mempunyai kompetensi tinggi karena keahlian atau kompetensi akan dapat mendukung peningkatan prestasi kerja pegawai. Penilaian kinerja harus dilakukan untuk mengetahui prestasi yang dapat dicapai setiap pegawai. Dengan melakukan proses penilaian kinerja maka prestasi yang dicapai setiap pegawai dengan nilai baik sekali, baik, cukup atau kurang bisa diketahui.

Penilaian kinerja pegawai yang dilakukan di Kantor Pelayanan Administrasi Terpadu Kecamatan Pucuk digunakan untuk proses kanaikan pangkat, evalusi kinerja, pegawai berprestasi dan penyesuaian ijazah. Penilaian kinerja digunakan untuk mengevaluasi hasil kerja seluruh pegawai secara kuantitatif dan kualitatif dengan menggunakan kriteria komitmen yang dinilai jujur, loyal, tanggung jawab dan disiplin. Manajemen yang dinilai kepemimpinan, perencanaan, pengorganisasian dan pengarahan. Kerjasama yang dinilai komunikasi, beradaptasi dan berbagi informasi. Hasil kerja yang dinilai adalah kualitas dan kuantitas.
Banyaknya kriteria yang digunakan dalam proses penilaian kinerja pegawai menyulitkan pihak manajemen untuk memberi bobot setiap kriteria oleh karena itu dibutuhkan suatu metode yang tepat, oleh kerena itu diperlukannya strategi untuk meningkatkan kinerja pegawai pelayanan administrasi terpadu kecamatan (PATEN) sehingga peneliti tertarik melakukan penelitian dengan judul "Sistem Pendukung Keputusan Penilaian Kinerja Pegawai Pelayanan Administrasi Terpadu Kecamatan (Paten) Di Kecamatan Pucuk Menggunakan Metode AHP Berbasis Web".

Dalam pembuatan sistem pendukung keputusan kinerja pegawai Pelayanan Administrasi Terpadu Kecamatan (PATEN), bertujuan untuk melakukan rancang bangun dan implementasi sistem pendukung keputusan untuk mengetahui kinerja pegawai yang ada di Kantor Pelayanan Administrasi Terpadu Kecamatan Pucuk dengan menggunakan penghitungan AHP.

\section{METODE PENELITIAN}

Dalam penelitian ini ada bebrapa proses perancangan web yang dilakukan, yaitu sebagai berikut :

1. Studi Literatur

Sebuah metode yang didapatkan dari membaca buku maupun refensi bersumber 
dari internet, yang berkaitan dengan pembuatan web.

2. Desain

Sebuah proses yang dilakukan untuk membuat desain system dan desain antar muka media yang menarik dan mudah dimengerti.

3. Pembuatan Perangkat Lunak

Pembuatan perangkat lunak ini dilakukan dengan menggunakan program PHP MySQL.

4. Uji Coba

Setelah melakukan pembuatan program, kemudian tahap metode uji coba, pada metode ini dilakukan untuk menguji program untuk mengetahui kesalahan dan kekurangan yang ada.

5. Analisa

Tahapan analisa ini yakni meneganalisa manfaat program yang dibuat bagi pengguna.

\section{ANALISA DAN PERANCANGAN SISTEM}

Untuk melakukan penulisan ini langkah - langkah yang dilakukan adalah sebagai berikut :

\section{Analisis Kebutuhan}

Pengguna sistem ini dapat mempermudah pihak kepala dalam melakukan proses kuisioner terhadap pegawai. Penulis akan menganalisa proses yang berjalan di PATEN secara langsung.

a) Kebutuhan Perangkat Keras

Perangkat keras yang digunakan sebagai penunjang dalam uji coba sistem/rekomendasi perangkat dalam proses pembuatan sistem ini mempunyai minimum spesifikasi sebagai berikut :

1. Processor Intel Pentium Dual-Core

2. RAM $2 \mathrm{~Gb}$

3. Hardisk $160 \mathrm{~Gb}$

4. Sistem Operasi Minimal Microsoft Windows XP

5. Monitor, Keyboard, Mouse

Semua semua spesifikasi hardware diatas harus dalam kondisi optimal atau dalam kondisi baik. Sehingga tidak menggangu jalanya sistem.

b) Kebutuhan Perangkat Lunak

Kebutuhan perangkat lunak sebagai pendukung dalam menjalankan Pegawai Pelayanan Administrasi Terpadu Kecamatan (PATEN) di Kecamatan Pucuk Menggunakan Metode AHP adalah sebagai berikut ini:

1. OS Windows (XP atau 7)

2. MySQL

3. PowerDesigner

4. XAMPP

5. Web Browser (Google Chrome, Opera, Mozila)

c) Kebutuhan Informasi

Adapun kebutuhan informasi yang akan diberikan pada sistem analisis ini adalah :

a. Rekap data pegawai

b. Rekap data kepala/ketua

d) Kebutuhan Pengguna (User)

Sistem ini terdapat 2 pengguna yaitu pegawai dan kepala/ketua. Sebagai pegawai untuk proses melihat hasil kinerja, sedangkan sebagai kepala/ketua untuk mengolah data penilaian kinerja para pegawai.

e) Analisis Kelayakan Sistem Sistem ini dihadapkan bisa memberikan kemudahan kepada pegawai dalam melihat hasil penilaian kerja secara mudah.

f) Kelayakan Teknologi

Sistem yang baru ini diharapkan dapat membantu ketua/kepala meningkatkan kinerja pegawai serta membawa kemajuan pelayanan ke arah yang lebih baik.

\section{Desain Sistem}

Menguraikan konsep pemodelan sistem dan alasan kenapa pemodelan sistem perlu dilakukan sehingga program yang akan dikerjakan dapat berjalan dengan baik, dan maksimal sesuai dengan apa yang diharapkan.

1. Data Flow Diagram (DFD)

a) Diagram Arus Data (DFD) Level 0 


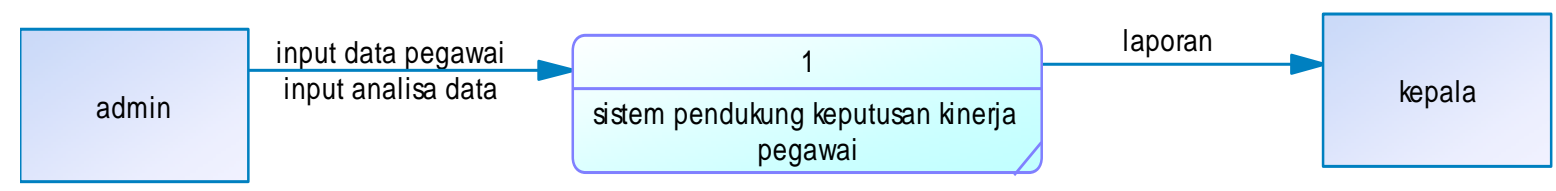

\section{Gambar 1. Desain Data Contex Diagram}

Admin melakukan proses input data pegawai, kriteria pegawai dan bobot ke sistem menghasilkan laporan ke kepala dan juga sistem menghasilkan laporan ke admin.

b) Flow Diagram (DFD)

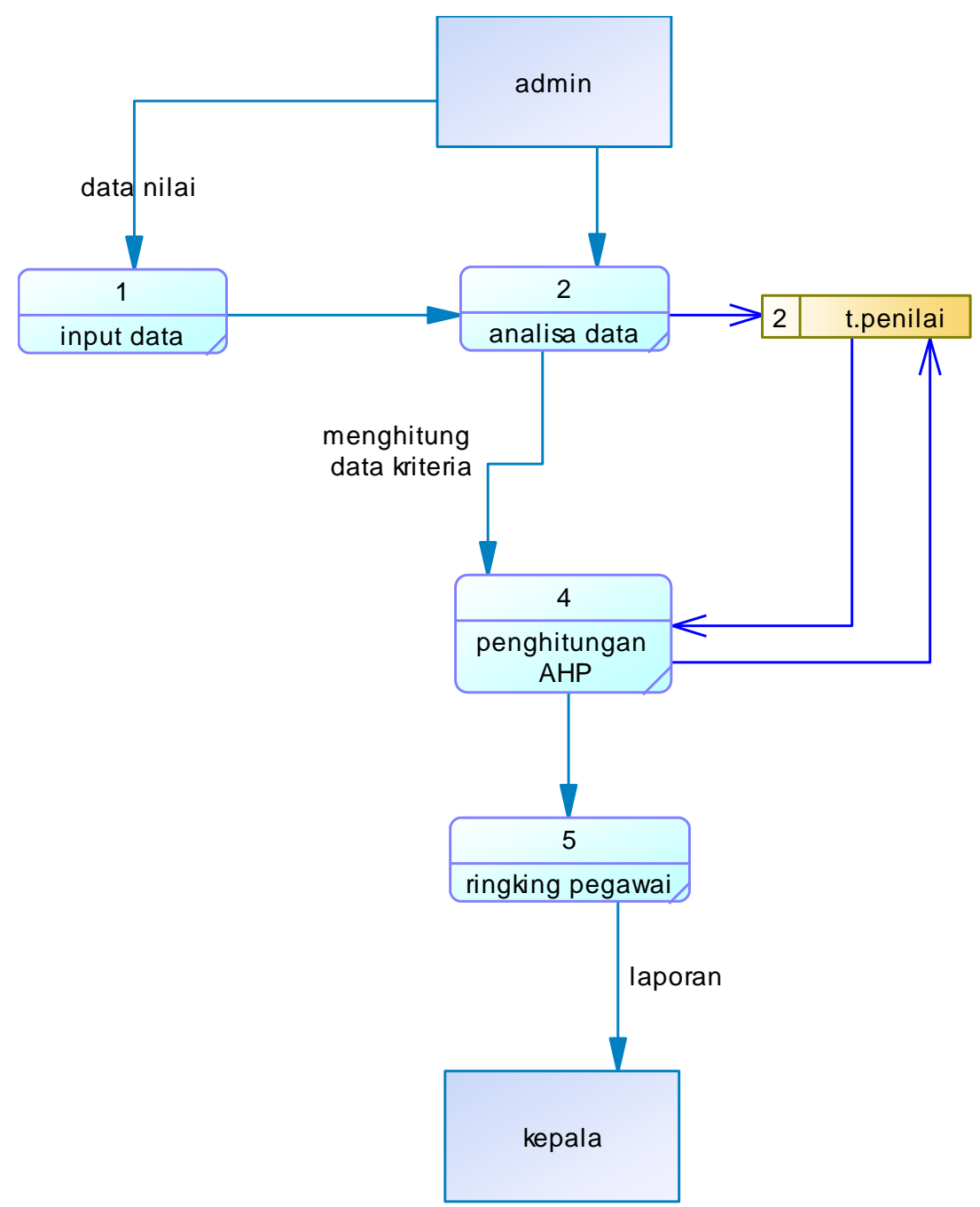

Gambar 2. Desain Data Flow Diagram Level 1

Admin melakukan 2 proses yaitu proses input data nilai dan input data analisa. Setelahh admin melakukan kedua proses tersebut sistem melakukan proses penghitungan AHP agar mengetahui hasil ringking pegawai kinerja tersebut dan menghasilkan laporan. 


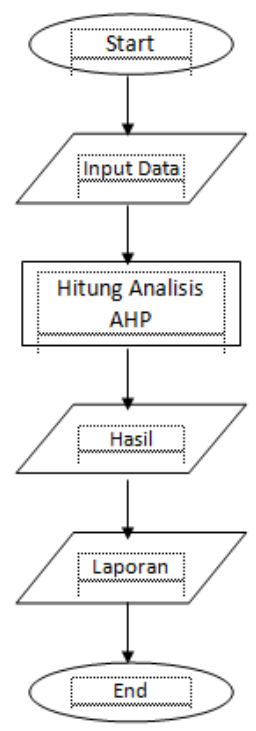

Pada alur Flowchart di atas mengambarkan langka dan situasi tahapan user maupun admin dalam mengoprasikan aplikasi tersebut.

\section{CDM (Conceptual Data Modeling)}

CDM dipakai untuk mengambarkan secara detail struktur basis data dalam bentuk logika. Struktur ini independen terhadap semua sofware maupun struktur data storage tertentu yang digunakan dalam sistem ini. CDM terdiri dari objek yang tidak diimplementasikan secara langsung ke dalam basis data yang sesungguhnya.

Gambar 3. Flowchart

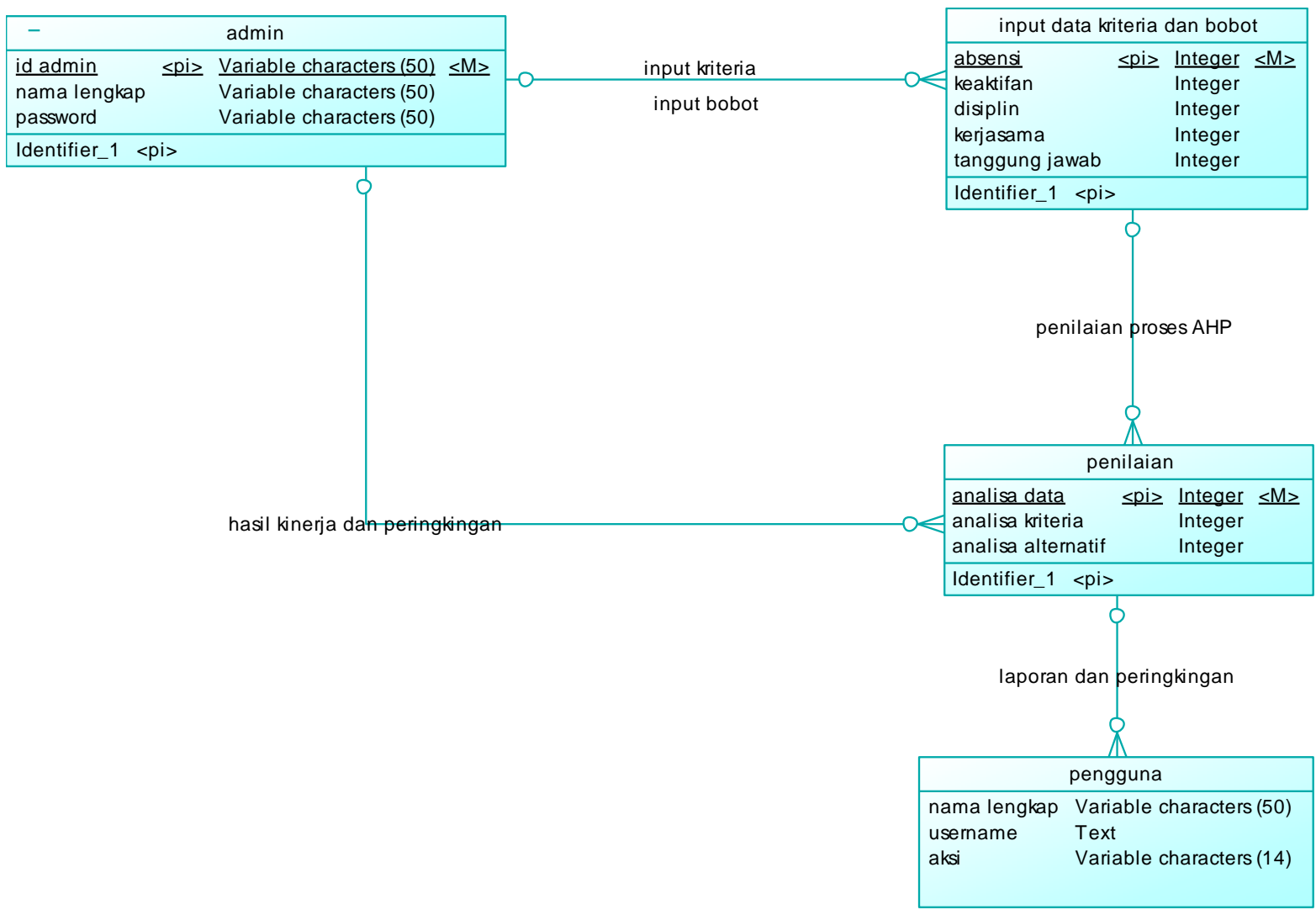

Gambar 4. CDM (Conceptual Data Modeling)

\section{Desain Interface}

a) Form Login

Form ini merupakan halaman utama pada program, pada form ini terdapat form login untuk masuk dalam aplikasi. 


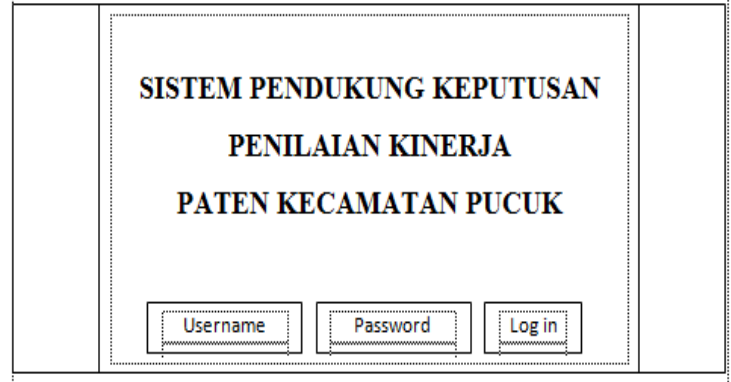

Gambar 5. Gambar Tampilan Utama

b) Menu utama

Form Menu utama terdapat pilihan menu Input Data, Analisa Data, Pembobotan dan Hasil Penelitian.

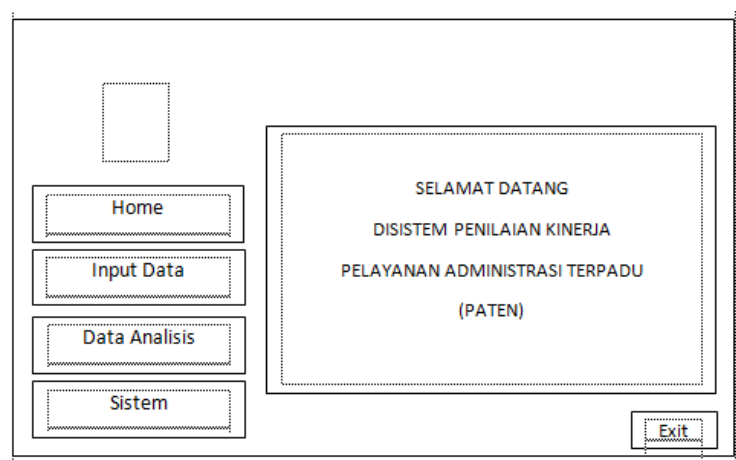

Gambar 6. Tampilan Utama

c) Input Data

Form ini berguna untuk mengisi data nilai, data kriteria dan data alternatif dari kinerja pegawai PATEN.

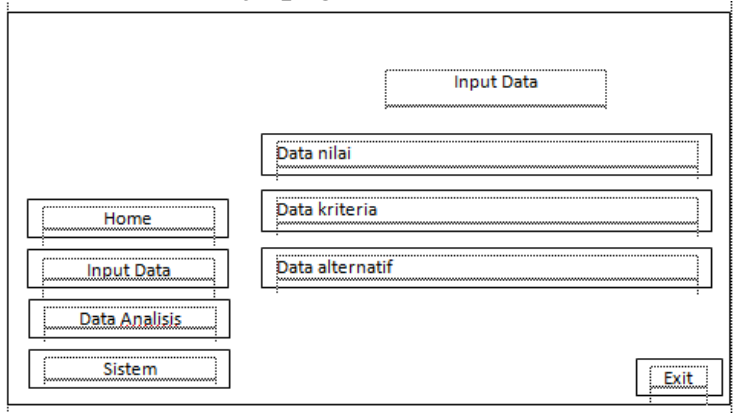

Gambar 7. Tampilan Input Data

d) Analisis Data

Form ini berisi dari hasil analisa kriteria, analisa alternatif, ringking dan laporan.

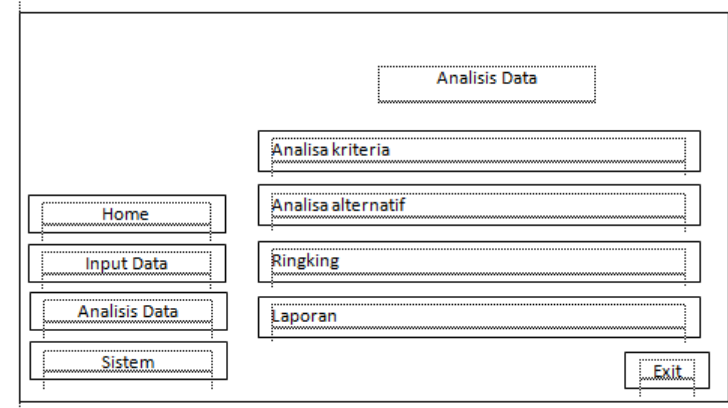

Gambar 8. Tampilan Analisis Data

e) Sistem

Form ini berfungsi sebagai menamba manejer pengguna dalam sistem tersebut.

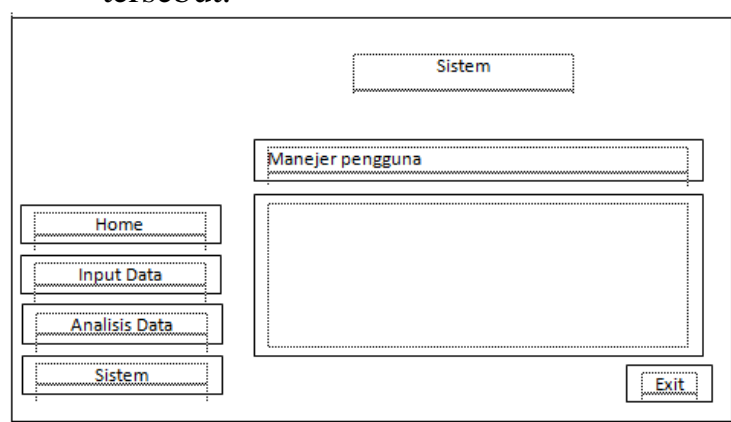

Gambar 9. Tampilan Sistem

\section{IMPLEMENTASI}

Impelementasi merupakan tahapan dimana sistem siap dioperaskan pada kondisi yang sebelumnya, sehingga akan diketahui apakah sistem yang telah dibuat benar-benar sesuai dengan apa yang sudah direncanakan. Sistem tersebut juga harus mampu berjalan dengan baik dan dalam keadaan perfoma yang baik pula. Pada impelementasi perangkat lunak ini akan dijelaskan bagaimana program Sistem Pendukung Keputusan Penilaian Kinerja Pegawai Pelayanan Administrasi Terpadu Kecamatan (Paten) Di Kecamatan Pucuk Menggunakan Metode AHP Berbasis Web ini bekerja, dengan memberikan tampilan form-form yang dibuat dan sesuai dengan analisa desain proses serta perancangan yang telah dijelaskan sebelumya.

Aplikasi Sistem Pendukung Keputusan Penilaian Kinerja Pegawai Pelayanan Administrasi Terpadu Kecamatan (Paten) Di Kecamatan Pucuk Menggunakan Metode AHP ini dalam impelementasinya dibatasi pada pembuatan program dengan proses menyimpan, mengubah, mengedit, dan menghapus data yang berupa input data, 
analisis data admin dan proses penghitungan rangking kinerja menggunakan metode AHP.

\section{HASIL DAN PEMBAHASAN Pengujian Program}

Tujuan dilakukan uji coba sistem adalah untuk mengetahui apakah sistem yang dibangun sudah selesai dengan perancangan yang telah dibuat pada tahap sebelumnya.Agar sistem berjalan dengan lancar diperlukan pengujian secara aktif dan kontinu agar menghasilkan data yang benarbenar akurat.Dengan demikian kesalahankesalahan yang ada pada sistem dapat diantisipasi.

\section{Pengujian Blackbox dan White Box}

Black Box Testing adalah pengujian yang dilakukan hanya mengamati hasil eksekusi melalui data uji dan memeriksa fungsional dari perangkat lunak. Pengujian Black Box merupakan pengujian dengan tempilan (interface) yang tidak sesuai (eror). Adapun beberapa uji coba yang dilakukan.

a. Pengujian Login Member Area

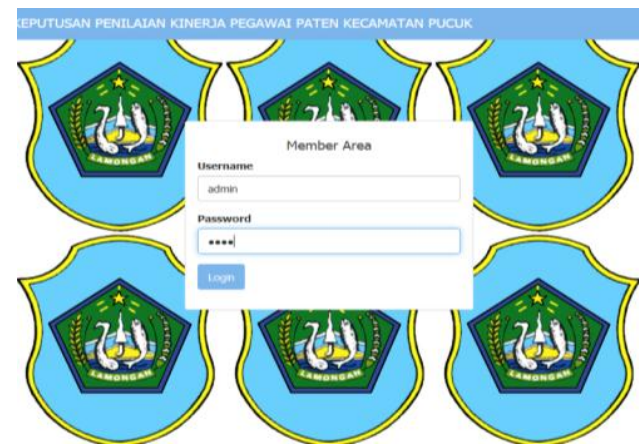

Gambar 10. Halaman Blackbox Login

Merupakan pengujian yang menampilkan tampilan halaman login dalam berisi dua kolom yaitu kolom username dan password dan pabila pengguna memasukan username dan password salah maka akan muncul tampilan seperti gambar di bawah ini.

Gagal Total

Gambar 11. Halaman Gagal Masuk Login Salah

Dan apabila login berhasil maka akan masuk dan muncul tampilan halaman menmu utama dalam sistem seperti gambar berikut :

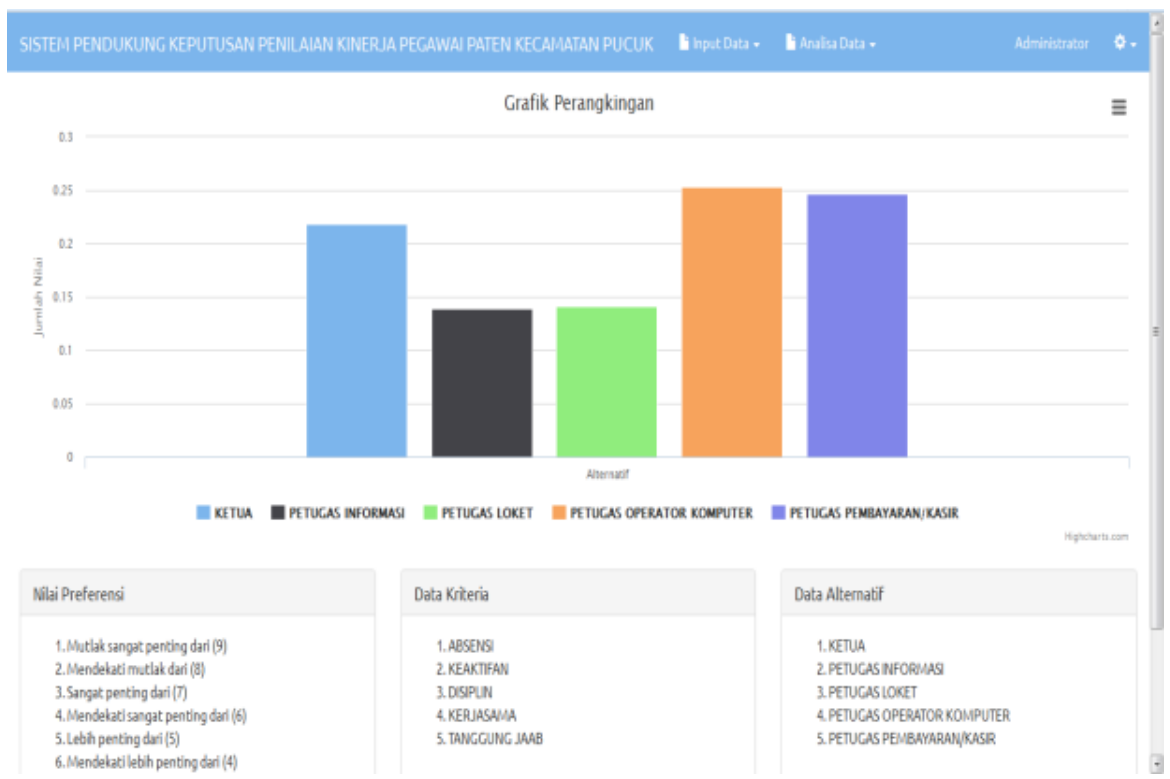

Gambar 12. Halaman Login Berhasil Menu Utama 
Tabel 1. Uji coba Login

\begin{tabular}{lllll}
\hline Prosedur & Masukan & $\begin{array}{c}\text { Output } \\
\text { yang } \\
\text { dirancang }\end{array}$ & Kriteria & Hasil \\
\hline Login & username & Masuk ke & Jika berhasil, & Berhasil \\
& dan & menu & akan tampil & masuk \\
& password & utama & menu utama & ke \\
& & & sistem, jika & menu \\
& & & tidak menu & utama \\
& & & & \\
& & & & \\
& & & &
\end{tabular}

b. Pengujian Input Data

Input Data merupakan pengujian yang menampilkan tampilan halaman tambah, edit dan hapus data. Berikut contoh input data pada data nilai :

■Tambah Nilai Preferensi

Jumlah Nlai

1

Keterangan Nai

Sangegt Kurang

Dsmpan Trembal

Gambar 13. Halaman Tambah Nilai

Apabila pengguna menambahkan data nilan preferensi maka akan bertambah satu data baru, sehingga akan muncul pada gambar seperti di bawah ini :

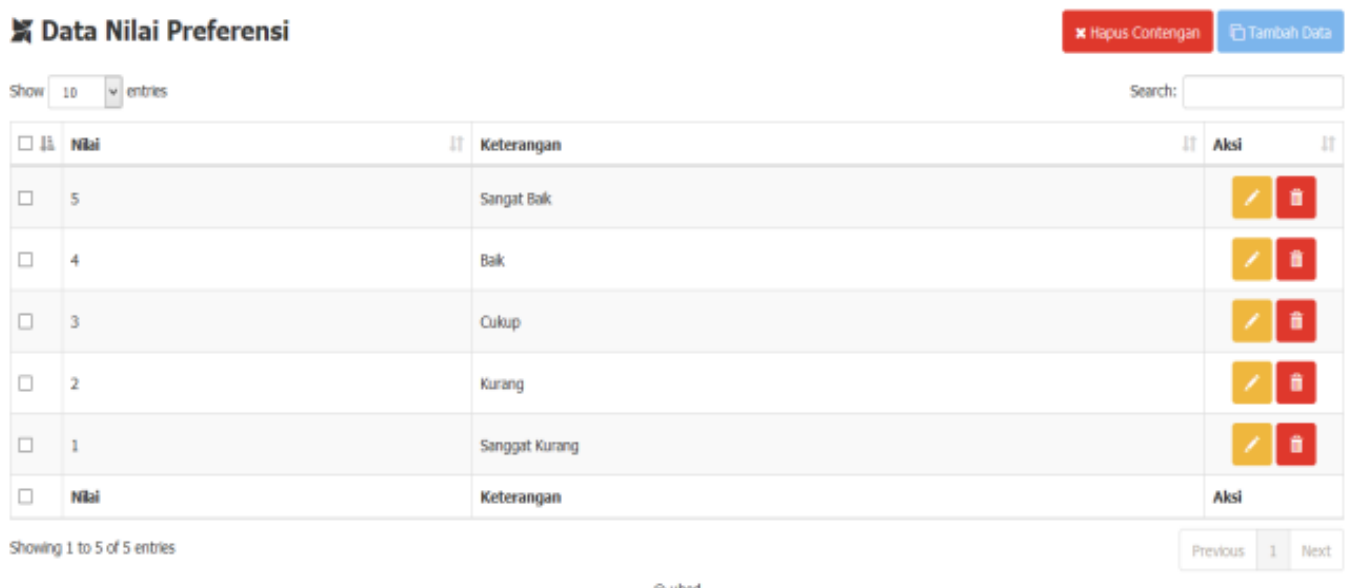

Gambar 14. Halaman Data Nilai Preferensi

Dan apabila salah satu data akan di hapus akan muncul pringatan berupa kotak dialog seperti di bawah ini :

Yakin ingin menghapus data

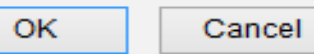

Tabel 2. Uji coba Input Data

\begin{tabular}{|c|c|c|c|c|}
\hline Prosedur & Masukan & $\begin{array}{l}\text { Output yang } \\
\text { dirancang }\end{array}$ & Kriteria & Hasil \\
\hline $\begin{array}{l}\text { Input } \\
\text { Data }\end{array}$ & $\begin{array}{l}\text { Masukan } \\
\text { jumah nilai } \\
\text { dan kriteria } \\
\text { nilai }\end{array}$ & $\begin{array}{l}\text { Menampilkan } \\
\text { hasil nilai } \\
\text { yang dudah } \\
\text { di rubah } \\
\text { maupun di } \\
\text { tambah }\end{array}$ & $\begin{array}{l}\text { Jika } \\
\text { berhasil, } \\
\text { akan } \\
\text { tampil } \\
\text { hasil edit, } \\
\text { jika tidak } \\
\text { bisa pilih } \\
\text { hapus }\end{array}$ & $\begin{array}{l}\text { Berhasil } \\
\text { menambah } \\
\text { data baru }\end{array}$ \\
\hline
\end{tabular}

c. Pengujian Analisa Data

Gambar 15. Tampilan Peringatan 
Dalam analisa data terdapat pilihan beberapa penghitungan seperti analisa kriteria yang menampilkan gambar di bawah ini :

\section{Analisa Kriteria}

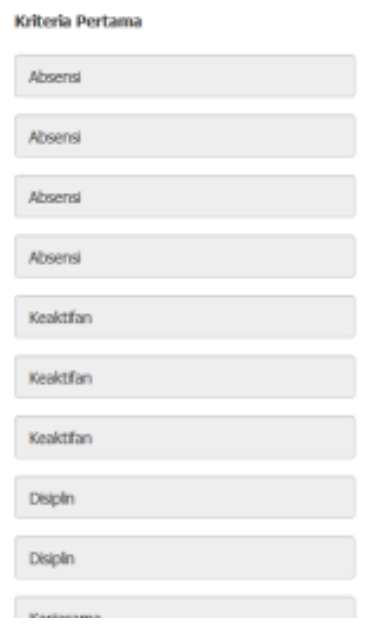

\begin{tabular}{|c|c|}
\hline 5- Sangat Bak & . \\
\hline 5 - Sangat bak & v \\
\hline 5 - Sangat Bak & v \\
\hline 5 - Sangat tak & . \\
\hline 5. Sungat Bak & $\checkmark$ \\
\hline S - Sangat bak & . \\
\hline 5- Sungat Baik & v \\
\hline 5- Sangat Eak & * \\
\hline 5- Singat Baik & 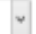 \\
\hline
\end{tabular}

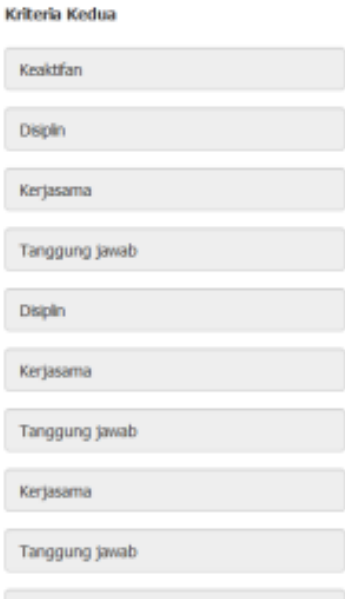

Gambar 16. Tampilan Peringatan

Berikut hasil dari penghitungan dari sistem komputer melalui perbandingan kriteria.

囲 Perbandingan Kriteria Hapus Semea Data

\begin{tabular}{|c|c|c|c|c|c|c|c|c|c|}
\hline Antar Kriterla & Absensi & \multicolumn{2}{|l|}{ Keaktifan } & \multicolumn{2}{|l|}{ Dksiphn } & \multicolumn{2}{|l|}{ Kerjasama } & \multicolumn{2}{|l|}{ Tanggung jawab } \\
\hline Absensi & 1 & 4.000 & & 5.000 & & 5000 & & 5000 & \\
\hline Keaktian & 0.250 & 1 & & 5.000 & & 5000 & & 5000 & \\
\hline Desiphn & 0.200 & 0.200 & & 1 & & 5000 & & 5000 & \\
\hline Kerjasana & 0.200 & 0.200 & & 0.200 & & 1 & & 5000 & \\
\hline Tanggung jawab & 0.200 & 0.200 & & 0.200 & & 0.200 & 1 & 1 & \\
\hline Jumbah & 1.850 & 5.600 & & 11,400 & & 16.200 & & 21.000 & \\
\hline Perbandingan & Absensi & Kcaktifian & Desiphn & & Kerjasama & & Tanggung jawa & & Bobot \\
\hline Absensi & 0.541 & 0.714 & 0.439 & & 0.309 & & 0.238 & & 0.448 \\
\hline Keaktflan & 0.135 & 0.179 & 0.439 & & 0.309 & & 0.238 & & 0.260 \\
\hline Desiphin & 0.108 & 0.036 & 0.088 & & 0.309 & & 0.238 & & 0.156 \\
\hline Kerjasana & 0.108 & 0.036 & 0.018 & & 0.062 & & 0.238 & & 0.092 \\
\hline Tonenuma thuoth & $n+m a$ & 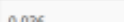 & nate & & $\mathrm{nnat2}$ & & ANAS & & aAsA \\
\hline
\end{tabular}

Gambar 17. Tampilan Peringatan

Tabel 3. Uji coba Analisa Data

\begin{tabular}{lllll}
\hline Prosedur & Masukan & $\begin{array}{c}\text { Output } \\
\text { dirang } \\
\text { ng }\end{array}$ & Kriteria & Hasil \\
\hline Analisa & Masukan & Menampil & Jika & Berhasil \\
Data & ke menu & kan hasil & berhasil, & menambah \\
& anallisa & nilai yang & akan & data baru \\
& & sudah & tampil & \\
& & dirubah & hasil, jika & \\
& & & tidak & \\
& & & maka & \\
& & & akan & \\
& & & sama & \\
\hline
\end{tabular}

Dalam merancang dan membuat sistem pendukung keputusan penilaian kinerja pegawai pelayanan administrasi terpadu kecamatan (paten) di kantor kecamatan menggunakan metode AHP, berikut akan dijelaskan mengenai perhitungan manual yang digunakan dalam sistem pendukung keputusan ini untuk dicocokkan dengan hasil perhitungan yang dilakukan oleh aplikasi, berikut adalah langkah-langkah perhitungan menggunakan metode AHP.

\section{Pembahasan}


Pembobotan Kriteria

Tabel 4. Matrix Berpasangan Kriteria

\begin{tabular}{c|c|c|c|c|c}
\hline Kriteria & Absen & Keaktifan & Disiplin & Kerjasama & $\begin{array}{c}\text { Tanggun } \\
\text { Jawab }\end{array}$ \\
\hline Absen & 1 & 2 & 3 & 4 & 5 \\
\hline Keaktifan & 0.5 & 1 & 2 & 3 & 4 \\
\hline Disiplin & 0.333333 & 0.5 & 1 & 2 & 3 \\
\hline Kerjasama & 0.25 & 0.3333333 & 0.5 & 1 & 2 \\
\hline Tanggung jawab & 0.2 & 0.25 & 0.33333333 & 0.5 & 1 \\
\hline Total & 2.283333 & 4.0833333 & 6.83333333 & 10.5 & 15 \\
\hline
\end{tabular}

Matriks perbandingan berpasangan diisi menggunakan bilangan untuk mempresentasikan kepentingan relatif dari suatu elemen terhadap elemen lainnya. Nilai elemen kolom yang dinilai didapat dari hasil bagi dengan nilai kriteria yang dinilai Jika suatu kriteria dalam baris bertemu dengan kriteria yang sama dalam kolom maka nilai elemen tersebut adalah 1 . Contohnya hasil 0.5 di kolom absensi, baris keaktifan didapat dari 1 dibagi 2. Nilai 1 di kolom absensi, baris absensi. Nilai 2 di kolom keaktifan, baris absensi.

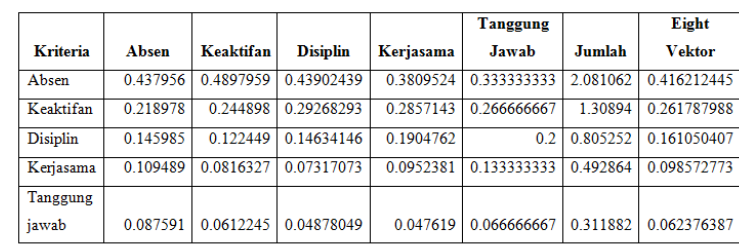

Gambar 18. Normalisasi Matrix Kriteria

Menghitung normalisasi matrix dengan rumus masing - masing elemen kolom dibagi dengan jumlah matriks kolom. Lalu jumlahkan setiap baris dan kolom. Nilai eigen vector didapat dari jumlah baris normalisasi dibagi dengan jumlah kriteria.

Menguji konsistensi setiap matiks berpasangan criteria

$$
\begin{aligned}
\lambda \text { maks } \quad= & ((2.283333 * 0.416212445)+ \\
& (4.0833333 * 0.261787988)+ \\
& (6.83333333 * 0.161050407)+ \\
& (10.5 * 0.098572773)+ \\
& (15 * 0.062376387))
\end{aligned}
$$

$=5.0904904 \mathrm{CI}((\lambda$ maks-n $) /(\mathrm{n}-1))$

$=((5.0904904-5) /(5-1))$

$=0.0226226$

$\mathrm{CR}=(\mathrm{CI} / \mathrm{IR})=(0.0226226 / 1.41)=$

0.0160444

Jadi, perhitungan ini konsisten karena $\mathrm{CR}=$ 0,1

\section{KESIMPULAN}

Berdasarkan hasil penelitian dan pengujian Sistem Pendukung Keputusan Penilaian Kinerja Pegawai Pelayanan Administrasi Terpadu Kecamatan (Paten) Di Kecamatan Pucuk Menggunakan Metode AHP Berbasis Web yang dilakukan oleh penulis, maka dapat diambil beberapa kesimpulan, yaitu Penelitian ini berhasil membuat sebuah sistem pendukung keputusan penilaian kinerja pegawai pelayanan administrasi terpadu kecamatan (PATEN) di kecamatan pucuk menggunakan metode AHP berbasis web dan Penelitian ini berhasil melakukan perangkat alteratif dari hasil penghitungan bobot nilai pegawai dengan menggunakan metode Analytical Hierarchy Process (AHP).

\section{REFERENSI}

[1] Ardiles Sinaga,M.T, Yessy Resti Melati, 2013, Sistem Pendukung Keputusan Pengelolaan Kinerja Karyawan Dengan Menggunakan Metode Fuzzy Logic Berbasis Web Di Pt.Premier Equity Futures Bandung

[2] Asaziduhu Gea, 2016,Analisa Kinerja Pegawai Menggunakan Fuzzy Logic

Dengan Metode Multi Atribute Decision Making

[3] Saefudin, Sri Wahyuningsih, 2014, Sistem Pendukung Keputusan Untuk Penilaian Kinerja Pegawai Menggunakan Metode Analytical Hierarchy Process (Ahp) Pada RSUD Serang, Vol-1 
J u r n a l Te knik A

V o l 110 N o . 1 M a r e t $2018,983-992$

ISSN 2085 - 0859

E-ISSN 2620 - 4770

Halaman ini sengaja dikosongkan 